\title{
Professores iniciantes: egressos de programas de iniciação à docência
}

Marli Eliza Dalmazo Afonso de Andrél (DD

\section{RESUMO}

A pesquisa objetivou analisar o processo de inserção profissional de professores iniciantes, egressos de três programas de iniciação à docência: Programa Institucional de Bolsas de Iniciação à Docência, Bolsa Alfabetização e Residência Pedagógica da Universidade Federal de São Paulo/Guarulhos. Os conceitos de socialização profissional, clima institucional e inserção profissional fundamentaram a pesquisa. A metodologia envolveu a realização de uma survey com 1.237 egressos provenientes de 18 instituições de ensino superior das regiões Nordeste, Centro-Oeste, Sul e Sudeste do país. Os resultados indicaram que $67 \%$ dos egressos estavam atuando na educação, muitos em escolas públicas (61\%); a maioria declarou receber apoio e reconhecimento dos colegas, gestores e pais de alunos e obter respostas positivas dos alunos. Metade dos respondentes declarou pouca satisfação com o número de alunos por classe e com o salário.

PALAVRAS-CHAVE

professor iniciante; inserção profissional; iniciação à docência.

'Pontifícia Universidade Católica de São Paulo, São Paulo, SP, Brasil. 


\section{BEGINNING TEACHERS: GRADUATES OF TEACHING INITIATION PROGRAMS}

\section{ABSTRACT}

This paper analyzes the process of professional insertion of beginning teachers, graduates of three initiation programs for teaching: Programa Institucional de Bolsas de Iniciação à Docência, Bolsa Alfabetização e Residência Pedagógica da Universidade Federal de São Paulo/Guarulhos. Theoretical references included concepts like professional socialization, institutional climate and professional insertion. The research methodology involved a survey of 1,237 graduates from 18 higher education institutions in the Northeast, Midwest, South and Southeast regions of the country. The results showed that $67 \%$ of the graduates were working in schools, and most of them in public schools (61\%); the majority of them declared having received support from peers, parents and managers, and positive feedback from pupils. Half the respondents reported little satisfaction with the number of students per class and salary.

KEYWORDS

beginning teachers; professional insertion; teaching initiation.

\section{PROFESORES INICIANTES: EGRESOS DE PROGRAMAS DE INICIACIÓN A LA DOCENCIA}

\section{RESUMEN}

El texto analiza el proceso de inserción profesional de profesores principiantes, egresados de tres programas de iniciación a la docencia: Programa Institucional de Bolsas de Iniciação à Docência, Bolsa Alfabetização e Residência Pedagógica da Universidade Federal de São Paulo/Guarulhos. La investigación utilizó fundamentos teóricos relativos a la socialización profesional, clima institucional e inserción profesional. La metodología involucró la realización de una encuesta con 1.237 egresados provenientes de 18 instituciones de enseñanza superior de las regiones Nordeste, Centro Oeste, Sur y Sudeste del país. Los resultados indicaron que 67\% de los egresos estaban actuando em la educación, muchos en escuelas públicas (61\%); la mayoría declaró haber recibido apoyo y reconocimiento de los colegas, padres y gestores y obtuvieron respuestas positivas de los alumnos. La mitad de los encuestados declaró poca satisfacción con el número de alumnos por clase y con el salario.

PALABRAS CLAVE

profesor principiante; inserción profesional; iniciación a la docencia. 


\section{INTRODUÇÃO}

A escolha do tema da pesquisa aqui apresentada tem origem nos resultados de um projeto anterior que investigou programas e políticas que visam promover a aproximação entre o espaço de formação profissional e o campo de trabalho, de modo que favorecesse o início da docência de jovens professores. Naquele momento foram analisados três programas: o Programa Institucional de Bolsa de Iniciação à Docência (PIBID), em âmbito federal; o Bolsa Alfabetização, do governo do estado de São Paulo; e o Bolsa Formação-Aluno-Aprendizagem, de um município paulista. Os três programas concediam bolsas a estudantes de licenciatura para desenvolver atividades em escolas da educação básica, sob a supervisão dos professores dos cursos de licenciatura e professores das escolas parceiras.

Os fundamentos teóricos da pesquisa estavam calcados na concepção de escola como espaço estruturante da formação docente, na necessária articulação entre os conhecimentos do campo profissional e da formação acadêmica e no desenvolvimento profissional como um processo contínuo de apropriação de saberes, atitudes, valores e conhecimentos para o exercício docente, além de condições apropriadas de trabalho, salário e carreira (Ambrosetti et al., 2015).

A metodologia do projeto incluiu análise de documentos legais referentes aos três programas e realização de grupos de discussão com 105 licenciandos-bolsistas, bolsistas dos cursos de pedagogia, educação física, biologia, letras, geografia, de 7 instituições de ensino superior (IES) (Universidade Federal de Pernambuco - UFPe; Universidade do Estado do Rio de Janeiro - UERJ; Universidade Federal de Uberlândia - UFU; Universidade de Taubaté — UNITAU; Universidade da Região de Joinville - UNIVILLE; Faculdade de Suzano - UNISUZ e Faculdades Atibaia -FAAT), 26 professores formadores e 12 professores supervisores de escolas públicas de educação básica. A escolha da técnica de grupos de discussão baseou-se em escritos de Flick (2004), Gatti (2005) e Weller (2006), buscando as opiniões de licenciandos e professores, construídas na interação grupal. Para orientar a discussão nos grupos, foi elaborado um roteiro que abrangia três grandes eixos: motivações para ingresso no programa; contribuições do programa para o desenvolvimento profissional dos participantes; e contribuições para o curso de licenciatura e para a escola.

Os resultados da análise documental indicaram que os três programas estavam ancorados em uma concepção de formação docente centrada na escola e no trabalho compartilhado de professores da universidade, professores da escola e aprendizes da docência. Mostraram ainda que havia, por parte dos elaboradores desses documentos, o propósito de elevar a qualidade do ensino nas escolas parceiras e nos cursos de licenciatura. No entanto, ficaram evidentes algumas diferenças entre os programas, seja:

- quanto ao âmbito de abrangência - o PIBID levava o bolsista a atuar em atividades da escola, enquanto nos outros programas a atuação dos licenciandos ficava mais restrita à sala de aula;

- quanto ao financiamento - o PIBID concedia bolsas para licenciandos, professores da universidade e professores da escola, os outros programas não concediam bolsas ao professor da escola. 
Daí surgiu a pergunta: Essas diferenças afetam a qualidade da formação? Não foi possível respondê-la com os dados produzidos por meio de levantamento de opiniões dos envolvidos, que em geral eram muito favoráveis e enfáticas quanto às contribuições dos programas para seu desenvolvimento profissional. Seria necessário recorrer a outros referenciais e procedimentos teórico-metodológicos que possibilitassem aprofundar as análises e responder à questão.

Os resultados referentes aos licenciandos indicaram que, em um primeiro momento, muitos buscaram os programas atraídos pela possibilidade de obter a bolsa, mas, à medida que se integravam nas atividades, percebiam quão importante era ter o contato com a realidade da escola e poderem atuar concretamente com a supervisão do professor da escola e com a orientação do professor da licenciatura. Quase todos declararam que a participação nos programas os fez reafirmar a escolha da profissão e alguns chegaram a verbalizar que a inserção nos programas fez despertar o interesse pela docência. Os aspectos valorizados pelos licenciandos foram comuns nos três programas: conhecer e atuar na realidade escolar; articular teoria e prática; desenvolver novas metodologias de ensino; refletir, criar e trabalhar coletivamente.

Os professores supervisores das escolas enfatizaram, em seus depoimentos, a oportunidade criada pelos programas de que eles voltassem a estudar, a atualizar-se e a aprender com os licenciandos. Já os professores formadores dos cursos de licenciatura ressaltaram a riqueza do trabalho compartilhado e as contribuições dele decorrentes, para repensar o curso de formação inicial.

A conclusão geral da pesquisa foi de que, do ponto de vista dos participantes, os três programas constituíam um avanço na formação inicial no sentido de diminuir a distância entre a formação acadêmica e o espaço de trabalho, possibilitar melhor articulação entre teoria e prática, desenvolver espaços coletivos de trabalho e contribuir para a elevação da qualidade dos cursos de licenciatura e da educação escolar.

Levando em conta os achados do projeto, desenhamos uma nova proposta de pesquisa para averiguar em que medida os programas de iniciação à docência promovem os benefícios apontados pelos seus participantes. Assim, a nova pesquisa teve como foco o impacto desses programas na prática docente de seus egressos, que seriam agora professores iniciantes. A literatura educacional (Marcelo, 2009; Nono, 2011; Vaillant e Marcelo García, 2012) indica que o ingresso na docência é marcado por muitos desafios que levam o professor a experimentar sentimentos variados, oscilando entre a sobrevivência e a descoberta, entre o choque da realidade e a alegria de se sentir capaz de ensinar.

Como os professores iniciantes, egressos dos três programas de iniciação à docência tiveram um processo de formação especialmente planejado para favorecer sua inserção profissional, levantamos as hipóteses de que, ao ingressarem na docência:

- teriam um processo de inserção profissional menos traumático que outros professores iniciantes, que não haviam passado por essas experiências;

- se sentiriam preparados para enfrentar os desafios do ensino e do trabalho na escola;

- saberiam onde buscar recursos para vencer as eventuais dificuldades; e

- teriam menos hesitações sobre permanecer ou não no magistério. 
Desse modo, a problemática da pesquisa ficou assim delineada: Como egressos de programas de iniciação à docência estão vivenciando a inserção profissional no magistério? Buscou-se verificar se os egressos tinham apoio dentro e/ou fora da escola; se eram bem recebidos pela equipe gestora, pelos pais de alunos e pelos colegas; se encontraram um clima favorável na escola; se tiveram dificuldade na gestão de sala de aula; se contavam com recursos materiais; e se estavam ou não satisfeitos com as condições de trabalho.

Essas questões nos levaram a definir como questão principal da pesquisa o seguinte: Como se processa o início da docência de egressos que passaram por programas especialmente delineados para favorecer sua inserção profissional?

\section{OBJETIVOS}

A questão de pesquisa nos direcionou a propor o seguinte objetivo geral: analisar processos de inserção na profissão docente, de egressos de programas de iniciação à docência. O objetivo geral desdobrou-se nos seguintes objetivos específicos:

- caracterizar os egressos de programas de iniciação à docência quanto à idade, escolaridade anterior e área do curso de licenciatura;

- mapear a destinação profissional dos egressos (estão atuando no magistério? Em que tipo de instituição?);

- analisar as condições de exercício vividas pelos egressos no início do magistério quanto ao tipo de apoio recebido, ao clima de trabalho na escola, à gestão de sala de aula, acesso a recursos didáticos e satisfação com as condições de trabalho;

- identificar elementos considerados pelos egressos/iniciantes facilitadores ou dificultadores da sua iniciação na profissão;

- verificar como os gestores das escolas avaliam a atuação dos egressos no desempenho do exercício profissional.

Apenas os três primeiros objetivos específicos são discutidos neste texto, que relata a primeira etapa da pesquisa. Os demais objetivos serão contemplados na etapa subsequente da pesquisa.

\section{JUSTIFICATIVAS E FUNDAMENTOS TEÓRICOS}

A temática dos professores iniciantes vem sendo um dos focos de estudo do nosso grupo de pesquisa nos últimos anos. Além da pesquisa-mãe que analisou a contribuição de programas de iniciação à docência na formação de futuros professores (André, 2016), trabalhos de mestrado (Poladian, 2014), de doutorado (Calil, 2014; Gonçalves, 2016; Pereira, 2015) e pós-doutorado (Nascimento, 2014), articulados ao projeto maior, foram desenvolvidos recentemente.

Por que é importante o estudo de professores iniciantes? Por um lado, porque é um tema muito pouco estudado no Brasil. Um exame inicial da literatura na área de formação de professores mostra que ainda são raros os estudos que se debruçam 
sobre esse tema. Mariano (2006, p. 12) mapeou textos apresentados nas reuniões nacionais da Associação Nacional de Pesquisa e Pós-Graduação em Educação (ANPEd) e nos Encontros Nacionais de Didática e Prática de Ensino (ENDIPEs), no período de 1995 a 2004, e verificou que, de um total de 6.978 textos, apenas 24 tinham como foco o professor iniciante. Essa constatação foi reafirmada por Pappi e Martins (2009) ao atualizarem o mapeamento dos textos apresentados na ANPEd (2005-2007), com o exame das teses e dissertações defendidas no período de 2000 a 2007. Com base na análise dos trabalhos revistos, as autoras chegaram à seguinte conclusão: "a temática corresponde a $0,5 \%$ dos estudos realizados na área da educação, em sentido amplo" (Papi e Martins, 2009, p. 256), o que revela a escassa atenção que o início da docência vem recebendo por parte dos pesquisadores brasileiros.

Mais recentemente, Correa e Portella (2012) atualizaram o mapeamento dos trabalhos apresentados na ANPEd e encontraram, entre as 198 produções do período de 2008 a 2011, apenas 4 com foco nos professores iniciantes, o que reitera as conclusões anteriores e sinaliza a necessidade de novos estudos na área.

Gonçalves (2016) também se dispôs a continuar o mapeamento de pesquisas sobre os professores iniciantes, revendo os textos apresentados na Reunião Nacional da ANPEd dos anos de 2012 a 2015, dos ENDIPEs, de 2012 a 2014, e do Congresso Internacional sobre Professores Principiantes e Inserção Profissional (CONGEPRINCI), de 2014, e concluiu que não só o tema ainda merece maior atenção, mas também pontuou que os resultados das pesquisas são recorrentes: voltam-se aos dilemas e tensões vividos no início da carreira, ao choque de realidade, aos processos de socialização e desenvolvimento profissional e reafirmam a ausência, no Brasil, de políticas e programas voltados aos professores que ingressam na docência.

Além dos resultados de pesquisa, a condição dos iniciantes tem sido discutida por autores nacionais e internacionais. Marcelo García (2010, p. 9), por exemplo, afirma que são muitas as tarefas a serem enfrentadas pelos iniciantes, tais como: procurar conhecer os estudantes, o currículo e o contexto escolar; planejar adequadamente o currículo e o ensino; começar a desenvolver um repertório docente que lhes permita sobreviver como professor; criar uma comunidade de aprendizagem na classe; e continuar desenvolvendo uma identidade profissional. Múltiplas e complexas tarefas!

Reconhecer que a aprendizagem da docência não se encerra na conclusão dos cursos de licenciatura, mas deve prosseguir ao longo da carreira, é um passo importante para que o iniciante não desanime diante das dificuldades e se disponha a buscar recursos e apoios necessários, que o façam prosseguir em seu processo de desenvolvimento profissional. Esse movimento, no entanto, não pode ficar restrito à iniciativa pessoal; ele deve encontrar eco nas instituições de ensino e nas políticas educacionais. O principiante precisa receber apoio e orientação no ambiente de trabalho, de modo que reconheça que a docência é uma profissão complexa, que exige um aprendizado constante e que para enfrentar as questões e os desafios da prática cotidiana é preciso continuar estudando, recorrer a colegas mais experientes, buscar apoio, dispor-se a aprender.

Cabe aos gestores das políticas públicas desenvolver programas especiais para os iniciantes ou criar condições para que as escolas possam desenvolver projetos que 
favoreçam a transição de estudante a professor ou o ingresso em uma nova cultura profissional. É importante que as políticas ou as inciativas institucionais sejam especialmente desenhadas para a inserção profissional, momento que se diferencia da formação inicial e continuada, pelas suas peculiaridades, de fase de transição, de integração na cultura docente, de inserção na cultura escolar, de aprendizagem dos códigos e das normas da profissão. Isso significa que não só devem ser elaborados e implementados programas de apoio à inserção na docência pelos gestores das políticas públicas, mas também pelos gestores das escolas, que devem propiciar a criação de um ambiente que favoreça a socialização profissional dos iniciantes.

\section{SOCIALIZAÇÃO PROFISSIONAL}

Em um texto muito provocativo sobre os desafios do trabalho docente, Nóvoa (2006) aponta a necessidade do cuidado com os iniciantes como um dos maiores desafios da profissão docente. Segundo ele, cuidamos muito mal dos jovens professores, pois ao ingressarem na docência eles vão para as piores escolas, têm os piores horários, recebem as piores turmas e são "lançados às feras", sem qualquer tipo de apoio. E o autor nos adverte: "se não formos capazes de construir formas de integração, mais harmoniosas, mais coerentes, desses professores, nós vamos justamente acentuar, nesses primeiros anos de profissão, dinâmicas de sobrevivência individual que conduzem necessariamente a um fechamento individualista dos professores" (Nóvoa, 2006, p. 14).

Esse fechamento ou isolamento profissional torna-se um fator de impedimento da socialização do jovem iniciante na profissão. A diversidade e a complexidade de situações que a dinâmica escolar oferece a ele podem dificultar seu percurso profissional e podem gerar sentimentos de insegurança e desejo de desistir da profissão.

Outros fatores que podem comprometer o processo de socialização profissional dos ingressantes são: a falta de estímulo ao trabalho coletivo e consequentemente a não promoção de relações com outros profissionais da escola e com os pais de alunos; a sobrecarga de tarefas que pode culminar no esgotamento docente; o número elevado de alunos por classe; a falta de material e de incentivo a práticas diversificadas; o não reconhecimento do esforço empreendido e do trabalho realizado pelo iniciante, bem como a ausência de ambientes colaborativos que facilitem e apoiem seu trabalho.

Estudos vêm evidenciando, em contrapartida, que as experiências vividas nas salas de aula na interação do professor com seus alunos parecem ser as mais marcantes ao longo do seu percurso profissional. Ao desempenhar sua função docente - a de fazer o aluno aprender - , o professor pode rever seus conceitos, buscar formas de atuação diante da realidade vivida e nesse movimento aprende a ensinar. Perceber que o seu esforço resulta em respostas positivas dos alunos, em aprendizagem, provoca sentimentos gratificantes e reforça o compromisso com a docência. Essas experiências, quando refletidas e compartilhadas com colegas, passam a ser formativas e provocativas da socialização do ingressante. Day (2004) defende a realização de reuniões de toda a escola, reuniões para troca entre os pares, 
como um momento para encorajar a divulgação de práticas, a partilha de saberes e fazeres, a colaboração e a reflexão sobre as experiências de sala de aula. Nesses momentos conjuntos, há oportunidade de conhecer atividades novas, práticas que deram certo com determinado tipo de alunos, perceber normas de funcionamento da escola que nem sempre são formalizadas, refletir sobre princípios que orientam as práticas.

Almeida e Ambrosetti (2009, p. 4) consideram que, ao ingressar na docência, os iniciantes começam a vivenciar seu processo de socialização profissional. Esse processo envolve uma relação dialética entre, por um lado, as condições sociais e institucionais colocadas ao trabalho docente e, por outro, as formas de exercer a docência, seja individual ou coletivamente, condições e formas estas que vão constituindo, além da cultura da escola, suas maneiras de ser e de agir como professor.

Ao considerarmos a afirmação de Canário (1998, p. 9), de que "a escola é o lugar onde se aprende a ser professor", fortalece-se o argumento da importância do contexto de trabalho para o processo de socialização e para a aprendizagem da docência.

As considerações e proposições dos autores citados incitaram-nos a fazer algumas indagações: Quais as condições que têm facilitado ou dificultado o ingresso e a socialização profissional dos professores iniciantes? Das estratégias que utilizam para o enfrentamento das dificuldades que surgem no dia a dia da sala de aula, quais têm contribuído para manter o entusiasmo e a permanência na profissão? E quais têm demandado um processo de reflexão e revisão de suas crenças e de suas práticas? Essas são algumas das questões que impulsionaram a presente investigação.

\section{A CULTURA E O CLIMA INSTITUCIONAL}

Um aspecto fundamental na fase inicial da carreira profissional são as condições facilitadoras ou dificultadoras que o iniciante encontra no ambiente de trabalho e que muitas vezes são decisivas para sua permanência ou não na profissão. Mesmo considerando que os egressos de programas de iniciação à docência já tenham tido oportunidade de conhecer a realidade escolar, sabe-se que é na experiência cotidiana de trabalho que a cultura e o clima institucional são revelados. Tanto a cultura como o clima institucional são produtos das relações vividas por todos os integrantes do coletivo escolar, que abrange não só os que atuam no interior da escola como também as interações com a comunidade externa à instituição e com as políticas educativas.

Pérez-Gómez (2001, p. 131) define a cultura institucional como "o conjunto de significados e comportamentos que a escola gera como instituição social”. Ainda, segundo o autor:

As tradições, os costumes, as rotinas, os rituais e as inércias que a escola estimula e se esforça em conservar e reproduzir condicionam claramente o tipo de vida que nela se desenvolve e reforçam a vigência de valores, de expectativas e de crenças ligadas à vida social dos grupos que constituem a instituição escolar.

Além disso, o autor completa: "É fácil compreender a influência que esta cultura tem sobre as aprendizagens vivenciais e acadêmicas dos indivíduos que nela 
vivem [...]" (Pérez-Gómez, 2001,p. 131). Acrescenta ainda que as interações significativas produzidas consciente ou inconscientemente na escola é que determinam seu modo de pensar, sentir e agir.

Para compreender a instituição social, que é a escola, Pérez-Gómez (2001, p. 131-132) considera necessário relacionar os aspectos macro e micro, "a política educativa e suas correspondências nas interações peculiares que definem a vida da escola”. Do mesmo modo, escreve o autor, para compreender as interações produzidas no interior da instituição, é preciso entender as relações entre as estruturas organizativas e as atitudes, os interesses, os papéis e comportamentos dos indivíduos e dos grupos. O autor conclui suas ponderações dizendo que "o desenvolvimento institucional se encontra intimamente ligado ao desenvolvimento humano e profissional das pessoas que vivem a instituição e vice-versa [...]" (Pérez-Gómez, 2001, p. 132).

Um conceito muito ligado ao da cultura institucional é o de clima organizacional ou clima de trabalho, que na perspectiva de Brunet (1992, p. 22) refere-se aos atributos que são perceptíveis pelas pessoas, em uma organização, sobre as suas formas de agir em relação a seus membros e à sociedade. Desse modo, o que importa é a percepção que a pessoa tem de seu ambiente de trabalho. Brunet ressalta que as pessoas é quem fazem da instituição aquilo que ela é, reforçando as conclusões de Pérez-Gómez. Com base nessas ponderações, pode-se indagar em que medida os iniciantes, egressos dos programas de iniciação à docência, são afetados pelo contexto institucional no que se refere ao apoio que o grupo de profissionais da escola oferece ao novo docente e em relação às condições encontradas na escola para o trabalho inicial do professor.

E quais condições institucionais e de trabalho seriam essas? Como elas afetam as oportunidades de aprendizagem profissional do iniciante? $\mathrm{O}$ fato de ter participado de programas de iniciação à docência terá facilitado sua interação no contexto escolar, especialmente na relação com os pares, gestores, alunos e no reconhecimento do seu trabalho pela equipe escolar? Essas questões orientaram a construção dos procedimentos e instrumentos metodológicos.

\section{METODOLOGIA DA PESQUISA}

A pesquisa associa duas dimensões: uma que cobre um grande volume de dados por meio de uma survey; e outra que utiliza estudos de caso, para uma investigação localizada e aprofundada de aspectos específicos, não explorados suficientemente na survey. Pode-se considerar que esta é uma pesquisa com métodos mistos, no sentido exposto por Moscoso (2017), em que dados quantitativos e qualitativos são usados de forma complementar, ou seja, realiza-se inicialmente um estudo panorâmico para conhecer a realidade de forma extensiva e em momento posterior são realizados estudos mais aprofundados, com procedimentos metodológicos múltiplos, nesse caso observação, entrevistas, registros escritos e análise documental.

A perspectiva epistemológica que orienta a pesquisa é a que valoriza o papel ativo do sujeito na produção do conhecimento e concebe a realidade como uma 
construção social (André,2005, p. 47), assim interessa conhecer o mundo dos sujeitos e os significados que atribuem às suas experiências cotidianas.

$\mathrm{Na}$ constituição do corpus da pesquisa, decidimos eliminar um dos programas analisados na pesquisa anterior, o da Secretaria Municipal de Jundiaí, porque estava em processo de reestruturação. Concomitantemente, decidimos integrar ao nosso corpus de análise o Programa de Residência Pedagógica da Universidade Federal de São Paulo (UNIFESP), que foi objeto da dissertação de mestrado de um dos membros do grupo de pesquisa (Poladian, 2014) e ainda porque seus propósitos são similares aos dos programas investigados.

Assim, os sujeitos/participantes da pesquisa são os egressos de três programas de iniciação à docência: PIBID, Bolsa Alfabetização e o Programa de Residência Pedagógica do curso de pedagogia da UNIFESP/Guarulhos, assim como os gestores das escolas em que atuam esses egressos. O Quadro 1 indica os programas, estados e cidades e IES que participaram da primeira etapa da pesquisa: são 7 IES federais, 2 estaduais, 6 comunitárias e 3 privadas.

Quadro 1 - Programas, estados, cidades e IES dos participantes.

\begin{tabular}{|l|c|c|c|}
\hline Programa & Estado & Cidade & IES \\
\hline PIBID & Santa Catarina & Joinville & UNIVILLE \\
\hline PIBID & Santa Catarina & Blumenau & FURB \\
\hline PIBID & Rio de Janeiro & Rio de Janeiro & UFRJ \\
\hline PIBID & Minas Gerais & Ituiutaba & UFU \\
\hline PIBID & Mato Grosso & Rondonópolis & UFMT \\
\hline PIBID & Pernambuco & Caruaru & UFPe e FABEJA \\
\hline PIBID & Ceará & Fortaleza & UECE e UFCE \\
\hline PIBID & Mato Grosso do Sul & Campo Grande & UEMS \\
\hline PIBID & Piauí & Teresina & UFPI \\
\hline PIBID & São Paulo & Santos & UNISANTOS \\
\hline PIBID & São Paulo & Taubaté & UNITAU \\
\hline PIBID e Bolsa & São Paulo & São Caetano & USCS \\
\hline Bolsa Alfabetização & São Paulo & Susano & UNISUZ \\
\hline Bolsa Alfabetização & São Paulo & Atibaia & FAAT \\
\hline Bolsa Alfabetização & São Paulo & São Paulo & F. SUMARÉ \\
\hline Residência Pedagógica & São Paulo & Guarulhos & UNIFESP \\
\hline
\end{tabular}

Universidade da Região de Joinville (UNIVILLE); Universidade Regional de Blumenau (FURB); Universidade Federal do Rio de Janeiro (UFRJ); Universidade Federal de Uberlândia (UFU); Universidade Federal de Mato Grosso (UFMT); Universidade Federal de Pernambuco (UFPe); Faculdade de Formação de Professores de Belo Jardim (FABEJA); Universidade Estadual do Ceará (UECE); Universidade Federal do Ceará (UFCE); Universidade Estadual de Mato Grosso do Sul (UEMS); Universidade Federal do Piauí (UFPI); Universidade Católica de Santos (UNISANTOS); Universidade de Taubaté (UNITAU); Universidade Municipal de São Caetano do Sul (USCS); Faculdade de Suzano (UNISUZ); Faculdades Atibaia (FAAT); Faculdade Sumaré; Universidade Federal de São Paulo (UNIFESP).

Fonte: Banco de dados da pesquisa.

Elaboração da autora. 


\section{ETAPAS DA PESQUISA}

A pesquisa, conforme mencionado, envolveu duas etapas, a saber: survey e estudos de caso de egressos em seu contexto escolar.

Survey é um estudo do tipo levantamento de dados que visa "descrever ou explicar características ou opiniões de uma população através de uma amostra representativa" (May, 2004, p. 109). A componente survey da presente pesquisa teve o propósito de conhecer quem são os egressos dos programas de iniciação à docência e as condições em que se inserem profissionalmente na docência. Trata-se de um estudo que abrange um grande número de participantes, o que foi viabilizado pela utilização de software específico - SurveyMonkey - que possibilitou a organização de banco de dados (cadastro dos egressos e contatos) e versão eletrônica do questionário. Integraram a survey egressos de 18 IES de 9 estados, em um total de 1.237 participantes. A escolha desses estados decorreu da possibilidade de acesso aos dados por parte dos integrantes da equipe de pesquisa. Para ter acesso aos $e$-mails dos egressos, foi necessário fazer contato com os responsáveis pelos programas nas IES. Para o levantamento de dados, que teve início em 2015, foram considerados os egressos que concluíram os programas de iniciação à docência nos anos de 2011, 2012, 2013 e 2014, já que esses programas de iniciação são recentes, pois começaram a operar a partir de 2007.

O instrumento de coleta de dados da survey, o questionário, foi elaborado tendo em vista caracterizar os egressos em relação à idade, escolarização anterior e área da licenciatura. Também foram incluídos no questionário, itens relativos à situação profissional dos egressos, atuação ou não no magistério, tipo de escola e/ ou rede em que trabalham, modalidade de ensino, tipo de vínculo empregatício, número de escolas e de horas de trabalho, tempo na escola, condições de exercício docente e razões para não estarem atuando no magistério. Foi elaborada uma versão preliminar do instrumento, que foi discutido pelo grupo de pesquisa, pré-testado em situação similar à real e, com base nas informações, foi reformulado. Após novo teste e novo julgamento, o instrumento foi inserido na Plataforma SurveyMonkey.

O processo de captação dos dados apresentou-se muito complexo: foi necessário o auxílio de um técnico em informática para comandar as idas e vindas do questionário. Definiu-se que um retorno de $30 \%$ de respostas seria o desejado, levando em conta o que se espera de uma survey dessa natureza. As repostas foram lentas, sendo necessário usar várias estratégias de captação, como mensagens pessoais, uso de Facebook, contato com os responsáveis pelos programas nas IES, tudo que se julgava importante para alcançar o índice de retorno definido. Em algumas IES o retorno foi melhor, em outras, mais difícil. Em todo caso, foram feitas cinco emissões (retirando os e-mails dos que já haviam respondido) para se obter o número final. Descobriu-se que houve muita mudança de $e$-mail dos bolsistas e que o número de respostas era maior nos casos em que os pesquisadores tinham tido contato pessoal com os licenciandos. O questionário foi enviado por via eletrônica a 3.095 egressos dos três programas, utilizando-se os e-mails disponíveis nas IES.

Na página inicial do instrumento havia uma breve apresentação do propósito da pesquisa e o Termo de Consentimento Livre e Esclarecido, que continha um 
caixa para ser assinalada no caso de concordância do respondente, que só então tinha acesso às questões. $\mathrm{O}$ instrumento foi estruturado em três partes: a primeira referia-se a dados de caracterização, a segunda continha questões sobre a atuação profissional do respondente e a terceira, informações sobre o exercício docente, com um total de 39 questões. Dessas questões, as 19 primeiras eram de múltipla escolha, em seguida havia 18 afirmações do tipo escala Likert, para indicar o grau de concordância ou discordância com a afirmação e, no final, havia duas questões abertas que indagavam se o respondente tinha intenção de permanecer ou não no magistério e se queria acrescentar algo sobre o início da docência.

Os dados do questionário foram tratados estatisticamente com auxílio do aplicativo estatístico Statistic Package for the Social Sciences (SPSS).

A segunda etapa da pesquisa consistiu em estudos de caso de escolas em que atuavam professores, egressos dos programas, em processo de inserção profissional. Foram estabelecidos como critérios de seleção dos casos: o professor ter respondido ao questionário, atuar em uma só escola, dispor-se a participar da pesquisa e ter o aceite da instituição escolar. A previsão inicial era a realização de pelo menos um estudo de caso por IES, incluindo observação nas escolas e salas de aula, assim como entrevistas com os gestores das escolas em que os egressos estavam atuando, obtenção de material das escolas e registros das observações. Alguns pesquisadores realizaram mais de um estudo de caso, o que redundou em um total de 20 estudos de caso com professores da educação infantil, ensino fundamental e ensino médio.

Neste texto são apresentados apenas os dados da survey porque os estudos de caso ainda não foram totalmente concluídos.

\section{RESULTADOS DA SURVEY}

O número total de respostas obtidas após as cinco emissões do questionário foi de 1.237 , o que significa um retorno de $40 \%$, considerado muito bom para esse tipo de pesquisa. Do total de respondentes, $43 \%$ eram provenientes de IES do Nordeste, $35 \%$ do Sudeste, $11 \%$ do Sul e $11 \%$ do Centro-Oeste. Tanto em termos do número total de participantes quanto de distribuição regional, pode-se dizer que os dados são bastante robustos.

Quanto às IES de origem dos respondentes, participaram: 7 federais, 2 estaduais, 6 municipais/comunitárias e 3 privadas. A concentração dos respondentes em IES públicas pode ser explicada pela história dos programas analisados: o PIBID estava inicialmente (2007 a 2009) voltado para os licenciandos das IES públicas e só em 2011 ampliou-se para outros tipos de IES; o Programa Residência Pedagógica está ligado a uma IES Federal; apenas o Bolsa Alfabetização abrangia IES privadas desde o início.

A procedência dos respondentes distribuiu-se pelas seguintes áreas de conhecimento da licenciatura: pedagogia (378), ciências biológicas e química (239), história e geografia (144), matemática e física (151), letras (123), artes (41), educação física (60), intercultural indígena (10), música (3) e ciências sociais (2); houve 86 respostas em branco. Embora sejam várias as áreas de licenciatura abrangidas, um grande número de respondentes se concentrava na área de pedagogia, o que pode 
ser explicado porque o Bolsa Alfabetização só inclui licenciandos de pedagogia e letras e a Residência Pedagógica abrange só o curso de pedagogia. Quanto ao número de respondentes das áreas de ciências biológicas e química, pode-se atribuir ao início da implantação do PIBID, que se voltava aos cursos de licenciatura em ciências e matemática.

Os dados relativos à caracterização dos egressos indicaram que 39\% tinham menos que 24 anos, $35 \%$ estavam na faixa de 24 a 29 anos, $17 \%$ tinham entre 30 e 39 anos e os demais (8\%) estavam com idade superior a 40 anos. Esses dados revelaram um quadro de ex-licenciandos jovens, a não ser pelos respondentes de uma IES privada que tinha mais egressos na faixa etária mais alta. Essa IES oferecia um grande número de vagas para o curso de pedagogia e cobrava mensalidades muito baixas, o que atraía candidatos afastados dos bancos escolares há algum tempo. Outra informação importante verificada foi de que muitos egressos cursaram tanto o ensino fundamental quanto o ensino médio em escola pública $(71 \%$ e $72 \%$, respectivamente). Pode-se inferir que esses egressos não eram provenientes de camadas socioeconômicas abastadas, uma vez que tiveram sua escolarização na rede pública.

Uma questão de grande interesse na pesquisa era verificar se os egressos estavam atuando na área de educação, pois os programas de iniciação foram desenhados para fornecer formação mais qualificada visando contribuir para a melhoria da educação básica da rede pública e ainda para aumentar a motivação para o magistério. Os dados indicaram que $67 \%$ dos egressos estavam atuando na educação, com maior concentração na região Sudeste $(75 \%)$ e menor concentração na região Nordeste (61,6\%), diferença decorrente das médias discrepantes da IES Faculdade de Formação de Professores de Belo Jardim (FABEJA) (PE), em que apenas 25\% declararam atuar na escola, e da UFRJ, que registrou um percentual de $90 \%$ em exercício nas escolas. Complementar, mas não menos importante que a constatação de que a maioria dos egressos estava atuando em escolas, foi conhecer o tipo de instituição em que estavam atuando. Verificou-se que, entre aqueles que declararam estar atuando em escola, $61 \%$ estavam vinculados a escolas públicas, dado muito positivo porque revela que o investimento feito tem retorno para a educação pública.

Buscou-se detectar ainda a modalidade de ensino em que os egressos estavam atuando e verificou-se que $9 \%$ estavam na educação infantil, $11,2 \%$ no ensino fundamental I, $8 \%$ no ensino fundamental II e $12 \%$ no ensino médio. Os demais em uma combinação dessas modalidades. A inserção em uma modalidade de ensino relacionava-se, por um lado, ao tipo de programa de iniciação (a maioria dos ex- pibidianos estava atuando no ensino fundamental II e ensino médio) e, por outro lado, ao curso de licenciatura concluído (os licenciados em pedagogia estavam na educação infantil e ensino fundamental I, em sua maioria). Quanto ao tipo de vínculo trabalhista desses egressos: $27 \%$ declararam ter vínculo temporário; $15,4 \%$, celetistas; $14,3 \%$ se identificaram como servidores públicos concursados; e os demais com uma combinação de tipos ou deixavam a resposta em branco. A constatação de que $27 \%$ tinham contrato temporário causa preocupação, pois indica precarização de trabalho e um fator de insegurança profissional.

Outro dado revelado pelo levantamento foi de que $71 \%$ dos egressos estavam atuando em uma única escola, o que pode ser considerado um dado positivo em 
relação a condições de trabalho, pois atuar em mais de uma escola pode comprometer a qualidade do trabalho profissional e, em se tratando de docentes iniciantes, dificulta ainda mais o período de adaptação e de aprendizagem da docência.

Para complementar os dados da destinação profissional dos egressos, procurou-se conhecer, entre os que declararam não estar atuando na escola (354 ou 33\%), qual era sua situação profissional. Desse grupo, $47 \%$ disseram estar aguardando concurso ou oportunidade; $25 \%$ indicaram que continuavam seus estudos; $20 \%$ relataram estar atuando em outra área; e $8 \%$ apontaram motivos diversos. Ao responderem que estavam aguardando concurso ou oportunidade, os egressos revelaram interesse em permanecer na docência, o que é muito positivo. Sabe-se que os concursos não ocorrem com frequência e em alguns locais são quase inexistentes. Outra observação importante é que o fato de darem continuidade aos estudos não pode ser considerado um elemento negativo, pois evidencia desejo de se qualificar melhor e quiçá possam vir a assumir, no futuro, o magistério na educação básica.

Essa fase de pesquisa do tipo survey permitiu ainda investigar as opiniões dos egressos sobre as condições de exercício nas escolas em que estavam atuando. No quesito referente a ter reconhecimento e receber apoio dos colegas, da equipe gestora, dos próprios familiares e amigos e dos pais de alunos, a concordância em geral foi acima de $80 \%$, exceto quanto ao apoio dos pais de alunos $(68,2 \%)$, que ainda assim foi bastante alta. As respostas, em geral, indicaram que os egressos não sentiam falta de apoio, o que é surpreendente, pois há muitas pesquisas com professores iniciantes que revelam o contrário, como as de Giordan (2014), Giovanni e Guarnieri (2014), Giovanni e Marin (2014), Gonçalves (2016), Marcelo García (2010), Vaillant e Marcelo García (2012). Um percentual significativo (82\%) de egressos apontou, no entanto, que recorrereu a apoios externos, com familiares, amigos, cursos, ex-professores, blogs, o que parece revelar iniciativa, certo domínio da situação e uma atitude de segurança para ir buscar o recurso necessário na fonte mais adequada. Esse dado nos reporta aos princípios contidos nos documentos oficiais e na dinâmica de funcionamento dos três programas investigados, que preconizam o desenvolvimento de uma postura investigativa com os futuros professores. Saber fazer uma leitura da situação e detectar aquilo que é necessário conhecer melhor, assim como saber localizar fontes, recursos, ferramentas que auxiliem a responder a essas inquietações, são elementos essenciais de uma postura investigativa.

Quanto ao ambiente de trabalho, os dados também foram surpreendentes: apenas o quesito que indagava se havia resistência da escola para diferentes práticas pedagógicas recebeu concordância média (47\%), os demais dados revelaram que na opinião dos egressos a escola tinha um clima agradável (83\%), que era possível discutir a prática com colegas (81\%) e que havia acompanhamento da equipe pedagógica $(69,4 \%)$. Esses dados merecem ser comentados: por um lado, chama atenção a percepção dos iniciantes de que há resistência da escola perante novas proposições, o que nos remete ao alerta dos autores citados (Brunet, 1992; Pérez-Gómez, 2001) de que o clima organizacional afeta as relações e as ações que se desenvolvem na escola, o que pode vir a comprometer futuramente o desempenho dos iniciantes. Por outro lado, as afirmações dos egressos de sentirem um clima agradável na escola, de discutirem suas práticas com os colegas e receberem acom- 
panhamento da equipe gestora contradizem não só a percepção de resistência da instituição a práticas diferenciadas como também o que é apontado nas pesquisas sobre a inserção profissional na docência, de que os iniciantes não recebem apoio da equipe gestora e dos colegas quando chegam às escolas (Corrêa e Portella, 2012; Gonçalves, 2016; Mariano, 2006). Essas constatações nos inquietaram e sinalizaram que deveriam ser mais bem exploradas nos estudos de caso.

No quesito gestão de sala de aula, os dados mostraram experiências positivas dos egressos no contato com alunos (86\%) e na gestão de sala de aula (86\%). Em consonância com os resultados de outras pesquisas de iniciantes (Gonçalves, 2016), os egressos concordaram com a afirmação de que tiveram dificuldade para lidar com a indisciplina dos alunos (52\%), fato que é destacado na maioria das pesquisas, por professores iniciantes ou experientes. Quanto à concordância de 38\% dos egressos de que receberam as turmas mais difíceis da escola, é uma constatação que reitera escritos de vários autores (Marcelo García, 2010; Nóvoa, 2006), de que aos iniciantes são atribuídas as piores turmas, os piores horários, as escola mais vulneráveis.

$\mathrm{Na}$ questão de infraestrutura e recursos da escola, os dados evidenciaram que os egressos atuavam em escolas que contavam com materiais pedagógicos, recursos e equipamentos tecnológicos (78\% e 77,3\%, respectivamente), assim como infraestrutura física adequada (67\%). Esses dados corroboram o que Gatti, Barretto e André (2011) encontraram nos estudos de campo em que os depoentes não manifestaram insatisfação quanto à disponibilidade de recursos nas escolas.

Quanto a outras condições de trabalho, a maioria registrou que estava satisfeita com a carga de trabalho $(64,5 \%)$, embora quase a metade dos respondentes tenha discordado da afirmação de que o número de alunos por sala era adequado $(45,8 \%)$ e declarou-se pouco satisfeita com os salários (40\%).

Verificamos aqui que, mesmo se sentindo preparados para enfrentar os desafios cotidianos da docência, os iniciantes se depararam com problemas que afetam os professores em geral, sejam eles iniciantes ou não, tais como: lidar com a indisciplina e com o grande número de alunos em sala de aula e receberem salários não condizentes com a relevância da função.

Finalmente, os dados indicaram que $87 \%$ dos respondentes concordaram que a participação em programas de iniciação à docência facilitou sua inserção profissional, ou seja, a pesquisa revelou que a avaliação que os egressos fazem da contribuição dos programas para a sua atividade profissional é muito positiva. Essa constatação apenas reitera resultados de estudos que coletaram opiniões dos participantes de programas de iniciação à docência (Ambrosetti et al., 2015; André, 2016; Pereira, 2015; Poladian, 2014).

\section{A TÍTULO DE CONCLUSÃO}

Retomando as hipóteses formuladas no início da pesquisa, pode-se agora indicar os principais achados da survey, que foi realizada como primeira etapa da investigação. Como foi usada a metodologia dos métodos mistos, no sentido sugerido por Moscoso (2017), em que se define previamente a contribuição de cada 
um dos métodos e se objetiva a complementariedade dos dados, os resultados ora obtidos deram indicações para a próxima fase, a dos estudos de caso.

Uma das hipóteses iniciais desta pesquisa, quiçá a mais abrangente, era a de que, pelo fato de terem tido a oportunidade de participar dos programas de iniciação à docência, esses professores iniciantes teriam um processo menos traumático de ingresso na escola que aqueles que não passaram por essas experiências. Os dados colhidos até então nos permitem afirmar que os participantes da survey não revelaram o "choque de realidade", ou a fase de sobrevivência, caracterizada por Huberman (1992, p. 39) como o impacto sofrido na prática inicial pela tensão entre as ideias do professor e a realidade cotidiana da escola, pela dificuldade de conciliar ensino e gestão de sala de aula com a falta de materiais didáticos. O que se encontrou nas respostas referentes à situação de exercício docente dos egressos não foi o choque nem a sobrevivência, mas uma visão positiva da realidade encontrada nas escolas e um sentimento de autocompetência para lidar com as questões de sala de aula, assim como uma percepção de retorno positivo de seu trabalho com os alunos. Dessa constatação decorre um aspecto a ser mais bem explorado nos estudos de caso, quando se terá oportunidade de ouvir os gestores das escolas sobre o desempenho de professores iniciantes com passagem ou não pelos programas de iniciação. Essa é uma das questões a ser aprofundada, uma vez que a revisão de literatura de Gonçalves (2016) detectou prevalência dos sentimentos de sobrevivência, alternando-se ao de descoberta, no período de inserção profissional dos docentes. Os dados da presente pesquisa contradizem o que é apontado tanto nas revisões integrativas de pesquisas brasileiras quanto nas de outros países. A explicação para essa situação é de que os iniciantes se sentiam seguros e confiantes em sua formação para enfrentar as questões da docência.

Outra hipótese enunciada no início desta pesquisa era a de que os egressos se sentiriam preparados para enfrentar os desafios da prática escolar e, associada a essa, a de que saberiam onde buscar recursos para vencer os eventuais desafios e dificuldades da prática docente. Os dados obtidos nas respostas ao questionário, referentes às condições de exercício nas escolas, indicaram que os egressos se sentiam apoiados e reconhecidos pelos colegas, pela equipe gestora e pelos pais de alunos. Revelaram ainda que os egressos buscaram apoio fora da escola, com amigos, familiares, ex-professores, cursos, blogs, o que aparenta uma contradição. No entanto, pode-se interpretar esses resultados avaliando que, embora se sentissem afetivamente acolhidos na escola, perceberam que havia necessidade de buscar recursos profissionais fora dela, daí a procura por apoio. Essa iniciativa parece bastante positiva porque sugere um movimento de autonomia profissional (buscar aquilo que precisa para melhor realizar seu trabalho) e mostra indícios de uma postura investigativa (saber onde buscar aquilo que precisa). Tanto o princípio da autonomia quanto o da postura investigativa integram os propósitos dos três programas de iniciação à docência (André, Lucas e Martins, 2016; Poladian, 2014).

Os dados obtidos na survey nos auxiliaram ainda a conhecer melhor quais as características dos estudantes que concluíram os três programas de iniciação à docência: são agora professores iniciantes, na faixa etária de 30 anos, que completaram a licenciatura em diferentes áreas, como: pedagogia, ciências biológicas, 
letras, história, geografia, matemática, física, química, intercultural indígena, artes, música e educação física. A maioria frequentou o ensino fundamental e médio em escola pública. Essa caracterização indica que os programas de iniciação à docência estão não apenas abrangendo várias áreas da licenciatura, mas sobretudo contemplando uma população jovem, que provem de camadas pouco privilegiadas de nível socioeconômico, uma vez que em sua maioria tiveram a escolarização na escola pública. Revela, dessa forma, que os programas estão cumprindo uma função social e política, oferecendo oportunidade de qualificação em uma área que tanto necessita de profissionais bem formados, a educação básica.

Um objetivo crucial da pesquisa era conhecer a destinação profissional dos egressos, uma vez que naquele momento (2016) havia muita incerteza quanto à continuidade de um dos programas de iniciação, o PIBID. Havia uma alegação, do ministro da Educação, de que poucos egressos do PIBID estavam atuando na educação, daí que o retorno esperado para as redes de ensino não compensava os recursos financeiros gastos. Um pronunciamento público do ministro, Aloizio Mercadante, alegava que menos de $20 \%$ de ex-pibidianos estavam na escola.

Nesse momento foi fundamental ter os dados da survey que indicavam que, em 2016, 67\% dos egressos estavam atuando como docentes na educação básica, grande parte desses em escolas públicas (61\%), o que revelava uma situação muito diferente da aludida pelo ministro. Os resultados da survey foram imediatamente enviados pela coordenadora da pesquisa aos gestores responsáveis pela administração do PIBID no Ministério da Educação (MEC) e fundamentaram as reivindicações do grupo de intelectuais (Fórum dos Coordenadores Institucionais do PIBID FORPIBID) que lutava pela permanência do programa. A pesquisa teve, assim, uma função política, pois agora havia dados concretos extraídos de uma pesquisa que cumpria todos os critérios científicos. Após muitas audiências e debates, o programa foi mantido. Sabe-se que os dados da survey contribuíram concretamente para reforçar os argumentos de manutenção do programa.

Outros aspectos revelados pela pesquisa que merecem comentários são os referentes às dificuldades dos egressos para lidar com a indisciplina. A metade dos respondentes afirmou ter enfrentado dificuldade para lidar com a indisciplina dos alunos (52\%). Repete-se, assim, um problema que chega a ser quase universal, de enfrentamento da (in)disciplina escolar. Há muito ainda a pesquisar e descobrir sobre formas efetivas de atuação com jovens e crianças que frequentam os bancos escolares. Há ainda muitas discussões a serem empreendidas e muitas ações a serem tomadas quanto à função da escola no mundo de hoje, questão que subjaz o problema da (in)disciplina escolar.

Outro dado que chama atenção é o relativo às condições de trabalho dos professores. Quase a metade dos respondentes afirmou que não estava satisfeita com o salário e com o número de alunos nas turmas, questões que estão presentes em pesquisas de muitos países não só no que se refere a professores iniciantes, mas ao grupo profissional como um todo. Esse aspecto também foi mencionado nas respostas das perguntas abertas do questionário, que indagava se o egresso queria acrescentar algo. Um egresso afirmou: "arrumar emprego que me valorize pagando o piso e que não me explore tem sido bem difícil” (egresso UFRJ). Essa é uma luta 
que não pode ficar restrita ao coletivo profissional, deve envolver toda a sociedade, relaciona-se com uma questão mais ampla: a da valorização da profissão docente.

Finalmente, a maioria dos egressos (87\%) concordou que a participação nos programas de iniciação à docência facilitou o início do trabalho docente, ratificando a contribuição dessas iniciativas na formação de professores da educação básica.

\section{REFERÊNCIAS}

Almeida, P. C. A.; Ambrosettri, N. B. Profissionalidade docente: uma análise a partir das relações constituintes entre os professores e a escola. Revista Brasileira de Estudos Pedagógicos, Brasília: INEP, v. 90, n. 226, p. 592-608, set./dez. 2009.

Амbrosetti, N. B. et al. O PIBID e a aproximação entre universidade e escola: implicações na formação profissional dos professores. Atos de Pesquisa em Educação, Blumenau: FURB, v. 10, n. 2, p. 369-392, 2015. http://dx.doi.org/10.7867/18090354.2015v10n2p369-392

André, M. E. D. A. Estudo de caso em pesquisa e avaliação educacional. Brasília, DF: Liber Livro, 2005.

. Políticas de iniciação à docência para uma formação profissional qualificada. In: ___ (Org.). Práticas inovadoras na formação de professores. Campinas: Papirus, 2016. p. 49-70.

André, M. E. D. A.; Lucas, M. A.; Martins, F. P. O Projeto Bolsa-Alfabetização e o Programa de Bolsa de Iniciação à Docência: o que dizem os documentos oficiais? In: Novaes, A.; Villas Bôas, L.; Ens, R. T. (Orgs.). Formação de professores: das políticas à profissionalização docente. 1. ed. Curitiba: Editora Universitária Champagnat, 2016. v. 0, p. 129-154.

Brunet, L. Clima de trabalho e eficácia da escola. In: NóvoA, A. (Coord). As organizações escolares em análise. Lisboa: Publicações Dom Quixote; Instituto de Inovação em Educação, 1992. p. 125-140.

Calil, A. M. G. C. A formação continuada no município de Sobral/CE. 2014. 201f. Tese (Doutorado) - Pontifícia Universidade Católica de São Paulo, São Paulo, 2014.

Canário, R. A escola: o lugar onde os professores aprendem. Psicologia da Educação, São Paulo: USP, n. 6, p. 9-27, 1998.

CorrêA, P.M.; Portella, V.C.M. As pesquisas sobre professores iniciantes no Brasil: uma revisão. Revista Olhar do Professor, Ponta Grossa: UEPG, v. 15, n. 2, p. 223-236, 2012. http://dx.doi.org/10.5212/OlharProfr

Day, C. A paixão pelo ensino. Porto: Porto Editora, 2004.

Flick, U. Uma introdução à pesquisa qualitativa. 2. ed. Porto Alegre: Bookman, 2004.

Gatтi, B. A. Grupo focal na pesquisa em ciências sociais e humanas. Brasília, DF: Liber Livro, 2005. (Série Pesquisa em Educação).

Gatti, B. A.; Barretto, E. S.; André, M. E. D. A. Politicas docentes no Brasil: um estado da arte. Brasília, DF: UNESCO, 2011. 
Giordan, M. C. Professores iniciantes dos anos finais do ensino fundamental: desafios e dilemas. 2014.152f. Dissertação (Mestrado) — Universidade da Região de Joinville, Joinville, 2014. Giovanni, L. M.; Marin, A. J. (Orgs.). Professores iniciantes: diferentes necessidades em diferentes contextos. Araraquara: Junqueira e Marin, 2014.

Giovanni, L. M.; Guarnieri, M. R. Pesquisas sobre professores iniciantes e as tendências atuais da reforma da formação de professores: distância, ambiguidades e tensões. In: Giovanni, L. M.; Marin, A. J. (Orgs.). Professores iniciantes: diferentes necessidades em diferentes contextos. Araraquara: Junqueira e Marin, 2014. p. 5-12.

Gonçalves, G. S. Q. Inserção profissional de egressos do PIBID: desafios e aprendizagens no início da docência. 2016. 243f. Tese (Doutorado em Educação) - Pontifícia Universidade Católica de São Paulo, São Paulo, 2016.

Huberman, M. O ciclo de vida profissional dos professores. In: Nóvoa, A. (Org.). Vidas de professores. 2. ed. Porto: Porto Editora, 1992. p. 31-61.

Mariano, A. L. S. A construção do início da docência: um olhar a partir das produções da ANPEd e do ENDIPE. 2006. 156f. Dissertação (Mestrado em Educação) Universidade Federal de São Carlos, São Carlos, 2006.

Marcelo García, C. Desenvolvimento profissional: passado e futuro. Sísifo - Revista das Ciências da Educação, Lisboa: Universidade de Lisboa, n. 8, p. 7-22, jan./abr. 2009, p. 7-22.

. O professor iniciante, a prática pedagógica e o sentido da experiência. Formação Docente - Revista Brasileira de Pesquisas sobre Formação de Professores, Rio de Janeiro: ANPed; Belo Horizonte: Autêntica, v. 3, n. 3, p. 11-49, ago./dez. 2010.

May,T. Pesquisa social: questões, métodos e processos. 3. ed. Porto Alegre: Artmed, 2004. Moscoso, J. N. Los métodos mixtos en la investigación en educación: hacia un uso reflexivo. Cadernos de Pesquisa, São Paulo: Fundação Carlos Chagas, Campinas: Autores Associados, v. 47, n. 164, p. 632-649, abr./jun. 2017. http://dx.doi. org/10.1590/198053143763

Nascimento, M. G. C. A. O trabalho docente e a aprendizagem da profissão nos primeiros anos da carreira. 2014. 111f. Relatório (Pós-Doutoral) - Pontifícia Universidade Católica de São Paulo, São Paulo, 2014.

Nono, M. A. Professores iniciantes e o papel da escola em sua formação. Porto Alegre: Mediação, 2011.

NóvoA, A. Desafios do trabalho do professor no mundo contemporâneo. Nada substitui o bom professor. Palestra proferida no Sindicato dos Professores de São Paulo, São Paulo, 2006. Disponível em: <http://www.sinprosp.org.br/arquivos/novoa/livreto_novoa.pdf >. Acesso em: 10 jun. 2014.

Pappi, S.; Martins, P. L. O. Professores iniciantes: as pesquisas e suas bases teóricometodológicas. Linhas Crítica, Brasília: UnB, v. 15, n. 29, p. 251-269, jul./dez. 2009.

Pérez-Gómez, A. I. A cultura escolar na sociedade neoliberal. Porto Alegre: Artmed, 2001.

Pereira, M. L. A articulação entre universidade e escola: os saberes necessários para participação no projeto Bolsa Alfabetização. 2015. Tese (Doutorado em Educação) Pontifícia Universidade Católica de São Paulo, São Paulo 2015. 
Poladian, M. P. Estudo sobre o Programa de Residência Pedagógica da UNIFESP: uma aproximação entre universidade e escola na formação de professores. 2014, 128f. Dissertação (Mestrado em Educação: Psicologia da Educação) - Pontifícia Universidade Católica de São Paulo, São Paulo, 2014.

Vaillant, D.; Marcelo García, C. Ensinando a ensinar: as quatro etapas de uma aprendizagem. Curitiba: Editora UTFPR, 2012.

Weller, W. Grupos de discussão na pesquisa com adolescentes e jovens: aportes teórico-metodológicos e análise de uma experiência com método. Educação e Pesquisa, São Paulo: USP, v. 32, n. 2, p. 241-260, 2006. http://dx.doi.org/10.1590/S151797022006000200003

\section{SOBRE A AUTORA}

Marli Eliza Dalmazo Afonso de André é doutora em educação pela University of Illinois at Urbana-Champaign (USA). Professora da Pontifícia Universidade Católica de São Paulo (PUC-SP).

E-mail:marliandre@pucsp.br

Recebido em 5 de janeiro de 2018

Aprovado em 24 de julho de 2018 